\title{
Circummandibular Wiring: A Treatment Approach toward Management of Mandibular Fracture in Children
}

\author{
${ }^{1}$ Navin Kumar, ${ }^{2}$ Arvind Kumar, ${ }^{3}$ Shaguta Syreen, ${ }^{4}$ Swati Singh
}

\begin{abstract}
Understanding the repercussions of facial trauma on subsequent growth and the aftermath of the various methods of treating pediatric facial fractures is not something that those who treat adults have to take into account. Young bone possesses unique physical properties that coupled with the space-occupying developing dentition give rise to patterns of fracture not seen in adults. This results in a need for different forms of fixation for shorter periods of time. This case report documents trauma and follow-up care of a 4-year-old patient with mandibular fracture.
\end{abstract}

Keywords: Circummandibular wiring, Mandibular fracture, Maxillofacial injuries.

How to cite this article: Kumar N, Kumar A, Syreen S, Singh S. Circummandibular Wiring: A Treatment Approach toward Management of Mandibular Fracture in Children. Int J Clin Dent Res 2017;1(1):37-39.

\section{Source of support: Nil}

Conflict of interest: None

\section{INTRODUCTION}

Although the general principles of treatment of children's facial trauma are similar to those for adults, the technique differs. The experience of most clinicians is limited, as the incidence of facial trauma in children is low. The factors that are responsible for rarity of jaw fractures in children include elasticity of bone and a short thick condylar neck, which tends to resist fracture. However, a high tooth-tobone ratio encourages fracture through the developing tooth crypts, but it is seldom necessary to remove them. ${ }^{1}$ For the fracture of the body of the mandible in a pediatric patient, the fracture line extends downward and forward from the upper border of the mandible. Whereas, in adults, the direction of fracture line is usually downward

\footnotetext{
${ }^{1}$ Reader, ${ }^{2}$ Professor, ${ }^{3,4}$ Postgraduate Student

${ }^{1}$ Department of Oral and Maxillofacial Surgery, Purvanchal Institute of Dental Sciences, Gorakhpur, Uttar Pradesh, India

${ }^{2-4}$ Department of Pedodontics, Buddha Institute of Dental Sciences \& Hospital, Patna, Bihar, India

Corresponding Author: Arvind Kumar, Professor, Department of Pedodontics, Buddha Institute of Dental Sciences \& Hospital, Patna, Bihar, India, Phone: +910612234545, e-mail: drarvindverma29@gmail.com
}

and backward. ${ }^{2}$ Falls are the most common cause of pediatric maxillofacial injuries; fights and sport injuries are uncommon until the age of adolescence. ${ }^{3,4}$

\section{CASE REPORT}

A 4-year-old patient reported to the department with a history of fall from the first floor of a building while playing. The patient was conscious, and there was no history of convulsion or vomiting. Extraoral examination revealed swelling. Intraorally, there was complete set of deciduous dentition with fracture in left parasymphysis region with dearranged occlusion (Figs 1 and 2).

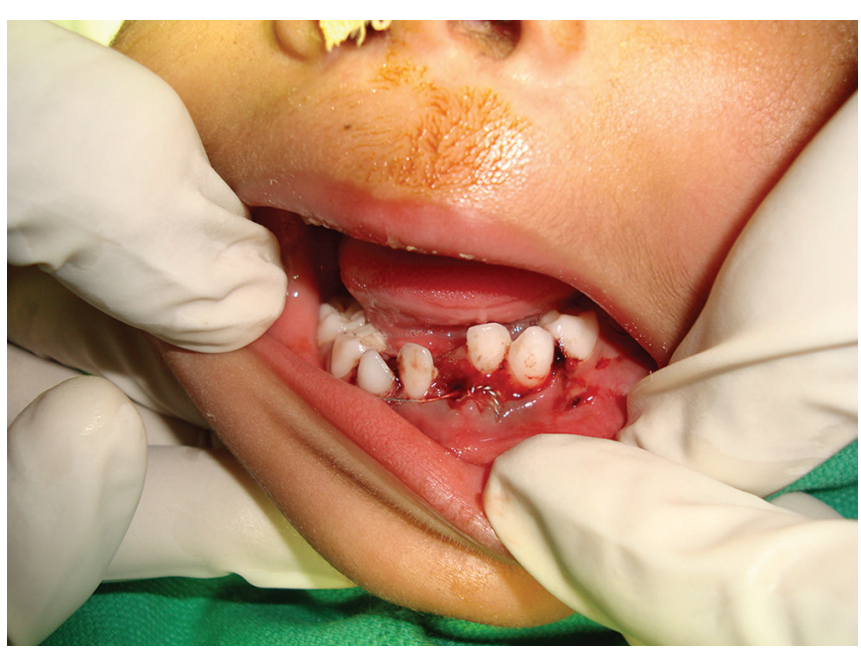

Fig. 1: Fracture on left parasymphysis region

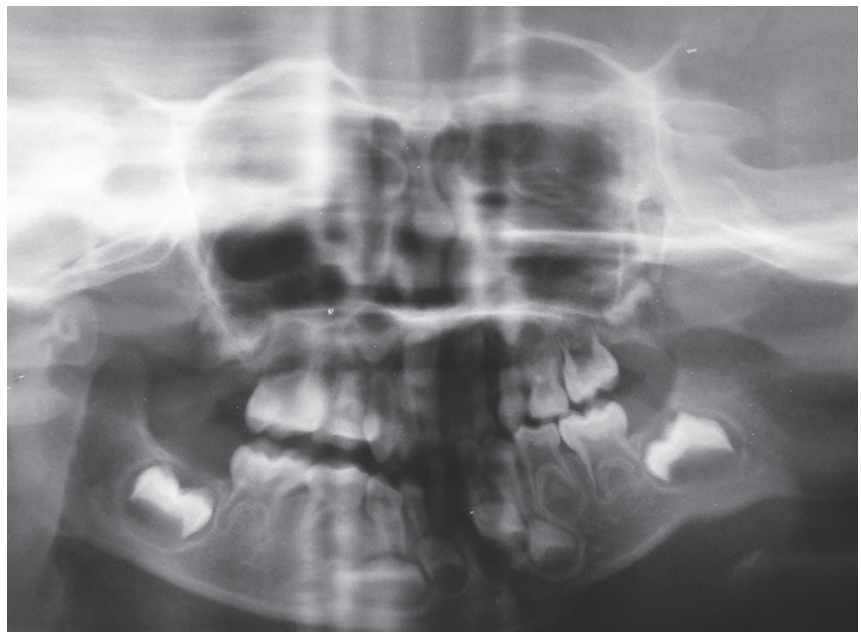

Fig. 2: Orthopantomogram X-ray showing fracture on left parasymphysis region 


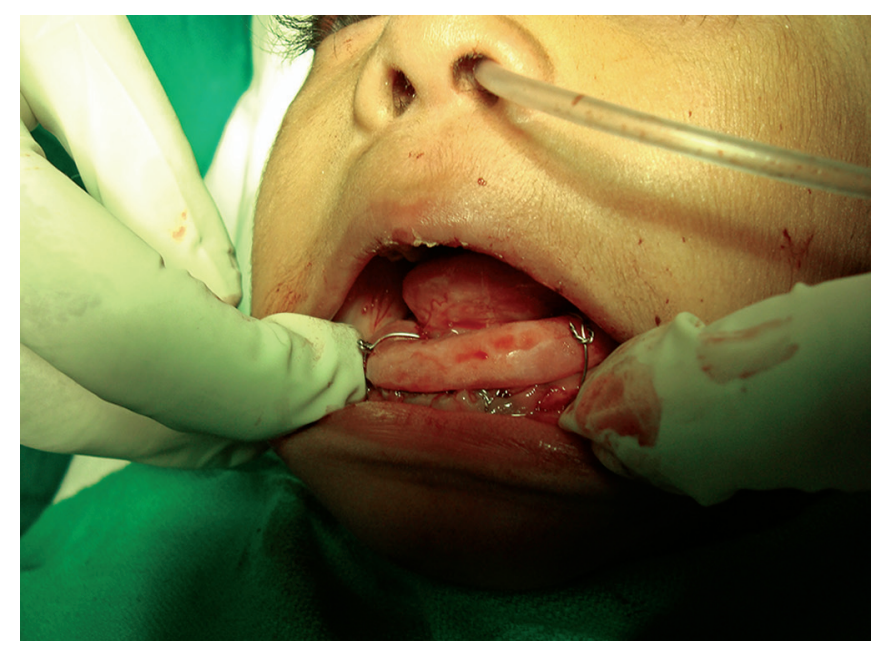

Fig. 3: Circummandibular wiring done bilaterally

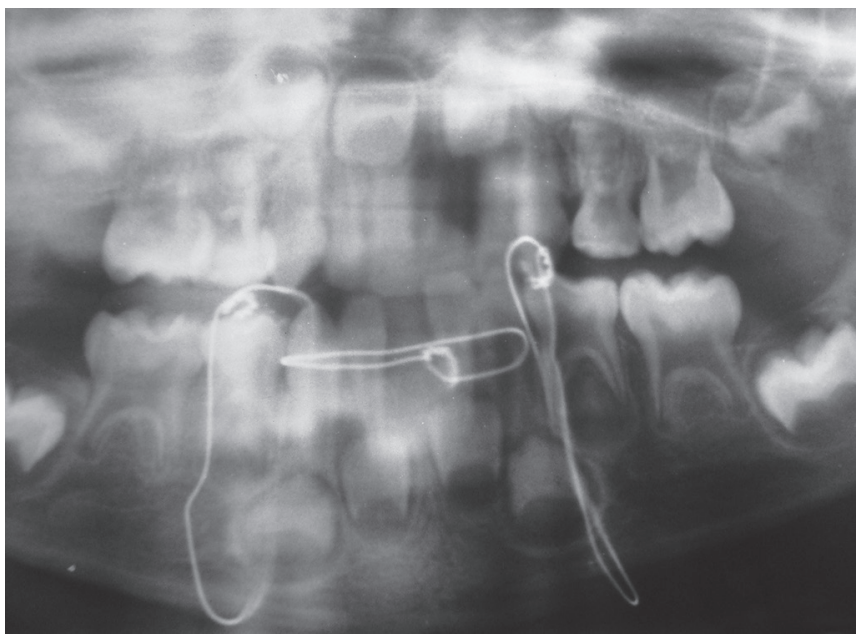

Fig. 5: Four weeks follow-up

\section{Circummandibular Wiring}

Since the fracture fragments were displaced, they were repositioned and secured with wire. Then an impression was made under short-acting general anesthesia. The splint was made with cold-cure acrylic, and the occlusal coverage of splint was desired to increase its rigidity. The splint was then secured to the mandible with circummandibular wiring. Circummandibular wiring was done by placing a small stab incision on the inferior border of the mandible on the right and left sides $4-5 \mathrm{~cm}$ from the midline. A 18 -gauze needle was used to enter lingually along the body of the mandible and piercing the lingual mucosa. The $26^{\prime \prime}$ gauze wire was fed and passed onto the buccal sulcus along the body of the mandible. The wire was held together and splint stabilized by winding the wire in clockwise direction (Figs 3 and 4). Intermaxillary fixation was generally not required, and the splint was removed after 4 weeks (Figs 5 and 6).

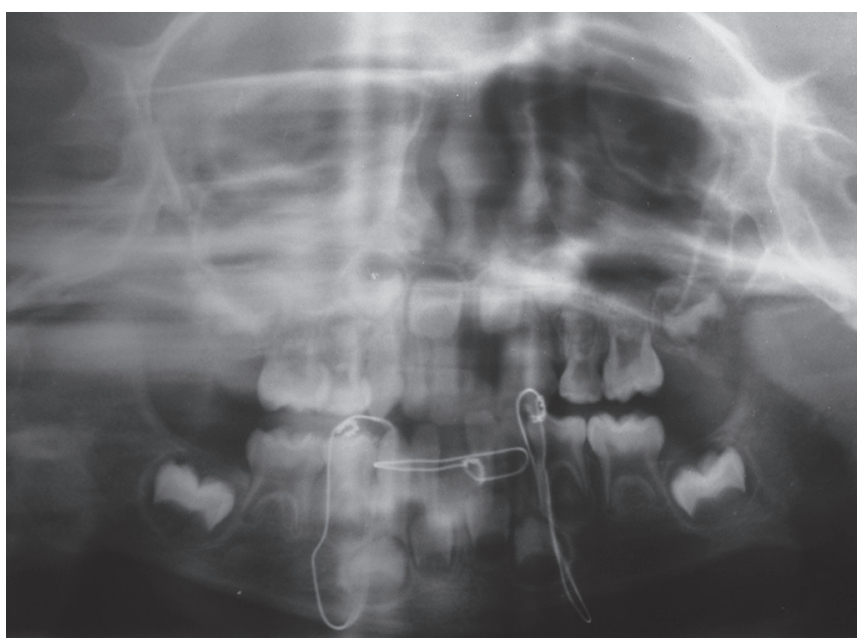

Fig. 4: Orthopantomogram X-ray showing circummandibular wiring done bilaterally

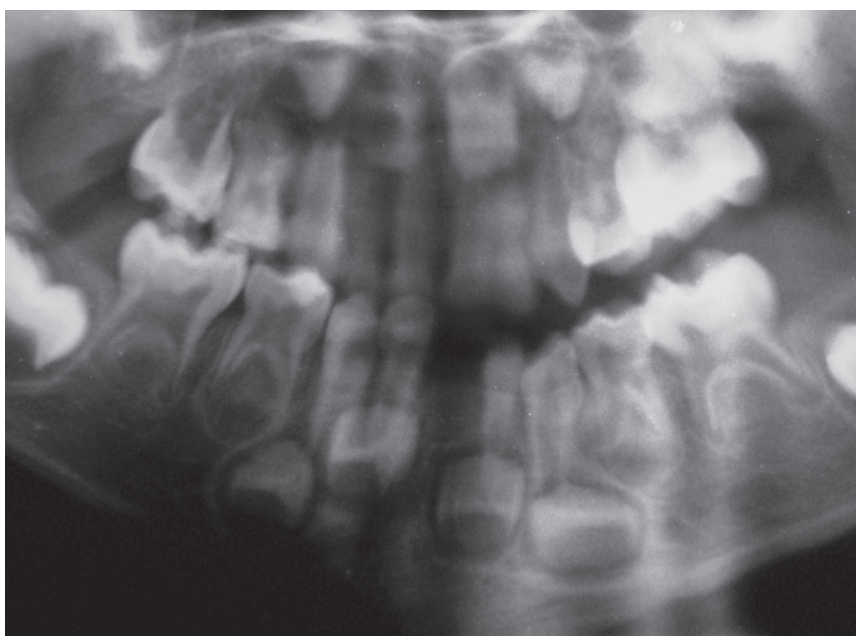

Fig. 6: Removal of wire after four weeks

\section{DISCUSSION}

Fractures in pediatric patients are frequently greenstick fractures and require no active treatment. ${ }^{5}$ The symphysis and parasymphysis displaced fracture are well managed with acrylic splint and circummandibular wiring. ${ }^{6}$ Displaced angle fracture required transosseous wiring, but these must be kept as close to the lower border of mandible as possible. Then, the patient is placed on maxilla-mandibular fixation for 2-3 weeks. ${ }^{7}$ Treatment of fracture of condyle is directed toward restoration of normal function as soon as possible after injury. In the initial postinjury period, jaw movement may be limited by pain; this can be relieved by rest and analgesics for first few days, or by a brief period of maxilla-mandibular fixation, followed by an active range of motion exercises. ${ }^{8}$

\section{CONCLUSION}

Continuing improvement in the management and outcome of pediatric facial trauma is dependent on 
high-quality research. Currently, much of our understanding is based on experience with adults and retrospective studies of children with high dropout rates and relatively short follow-up. Hence, long-term follow-up studies in pediatric patients are required for high success rate.

\section{REFERENCES}

1. Haugrh RH, Foss J. Maxillofacial injuries in pediatric patient. Oral Surg Oral Med Oral Pathol Oral Radiol Endod 2000 Aug;90(2):126-134.

2. James D. Maxillofacial injuries in children. In: Rowe NL, Willams JL, editors. Maxillofacial injuries. Churchill Livingstone. New York, 1970; p. 538-558.
3. Posnick J, Wells M, Pron G. Pediatric facial fractures: evaluating patterns of treatment. J Oral Maxillofac Surg 1993;51: 836-844.

4. Thorén H, Iizuka T, Hallikainen D, Lindqvist C. Different patterns of mandibular fractures in children: an analysis of 220 fractures in 157 patients. J Craniomaxillofac Surg 1992 Oct;20(7):292-296.

5. Myall R, Sandor G, Gregory C. Are you overlooking fractures of the mandibular condyle? Pediatrics 1987 Apr;79(4):639-641.

6. Das UM, Nagarathna C, Viswanath D, Keerthi R, Gadicherla P. Management of facial trauma in children: a case report. J Indian Soc Pedod Prev Dent 2006 Sep;24(3):157-160.

7. Hardt N, Gottsauner A. The treatment of mandibular fractures in children. J Craniomaxillofac Surg 1993 Jul;21(5):214-219.

8. Walker RV. Condylar fractures: nonsurgical management. J Oral Maxillofac Surg 1994 Nov;52(11):1185-1188. 